\title{
Simulating the Behavioural Effects of Welfare Reforms among Sole Parents in Australia*
}

\author{
Alan Duncan \\ School of Economics, University of Nottingham \\ and Institute for Fiscal Studies \\ and \\ Mark N. Harris
}

Melbourne Institute of Applied Economic and Social Research, The University of Melbourne and Central European University

Melbourne Institute Working Paper No. 6/01

\author{
ISSN 1328-4991 \\ ISBN 0734015097 \\ June 2001
}

\begin{abstract}
* This paper forms part of a larger project on behavioural microsimulation being carried at the Melbourne Institute, the University of Melbourne. We gratefully acknowledge partial support for the development of MITTS from the Department of Family and Community Services (FaCS). Two Visiting Research Scholar Grants from Faculty of Economics and Commerce Fund are also kindly acknowledged. We are grateful to John Creedy, Guyonne Kalb, Rosanna Scutella and Alan Woodland for valuable comments and suggestions. However, the views (and any errors or omissions) in this paper are those of the authors alone, and do not represent those of FaCS or associated departments.
\end{abstract}

Melbourne Institute of Applied Economic and Social Research

The University of Melbourne

Victoria 3010 Australia

Telephone (03) 83443701

Fax (03) 83445630

Email melb.inst@iaesr.unimelb.edu.au

WWW Address http://www.melbourneinstitute.com 


\begin{abstract}
This paper derives and estimates an econometric model of labour supply among sole parents in Australia, using modelling techniques which treat the labour supply decision as a utility maximising choice between a given number of discrete states. In estimation, we control for random preference heterogeneity as well as fixed and search costs. Using our econometric model, we look at the effects of actual and hypothetical welfare policy reforms on the employment choices of sole parents in Australia. The microsimulation results presented in this paper use the Melbourne Institute Tax and Transfer Simulator (MITTS), developed at Melbourne Institute of Applied Economic and Social Research.
\end{abstract}




\section{Introduction and Background}

The Australian Federal Government's stated commitment to tax reform (Costello (1998)) has re-ignited the debate on tax and welfare policy (see, inter alia Beer (1998a), Beer (1998b), Dawkins, Beer, Harding, Johnson, and Scutella (1998), Ingles (1998) and Keating and Lambert (1998)). One of the main concerns which informs this debate is the extent to which the tax and social security systems combine to give exceptionally high effective marginal tax rates (EMTR's). Indeed, EMTR's in excess of 100\% are not uncommon in the literature (Beer (1998b) and Ingles (1998)). Implicit in all such studies is the contention that high EMTR's create significant employment disincentives for low-wage workers and families with children. Nevertheless, it is rare to find studies which seek to quantify the extent of these employment disincentives. In the main, EMTR's are imputed assuming that hours worked do not change (that is, they are marginal). This may well be appropriate for particular demographics, prime-aged married men for example, whose labour market decision is invariably institutionally polarised at either full-time employment or unemployment (for those in the workforce). Other demographic groups, in particular sole parents, potentially enjoy a much more flexible labour supply choice. To characterise such groups' labour supply options through marginal effective tax rates (or replacement rates, or average tax rates) gives only a partial indication of work disincentives. A detailed microeconometric modelling approach is necessary to provide a fuller understanding of the employment effects of non-linear taxes and social security programs. The first objective of this paper is to analyse the labour market behaviour of sole parents in Australia, taking into account the full budget constraint faced by the individual. The second objective is to use this model to simulate the potential employment effects of a range of (actual and hypothetical) reforms which might affect sole parent households.

The choice of labour supply model for such an analysis must been informed by a number of considerations. Firstly, the model must deal appropriately with non-linear taxes in estimation. For many households (particularly one-parent families), the Australian tax and transfer system impacts quite heavily on the budget constraint. Income taxes, medicare, and various allowances, pensions and family payments combine to generate highly nonlinear and typically non-convex budget constraints. A basic model of the style of Hausman (1985) or Wales and Woodland (1979) is computationally infeasible in these 
circumstances. ${ }^{1}$

Secondly, the model specification must differentiate effectively among those observed not to work. One can observe at least three classes of non-worker: those who choose not to participate in work; those who are discouraged from seeking employment through fixed or search costs; and the involuntarily unemployed. Again, there are methods available to control for fixed $\operatorname{costs}^{2}$ and unemployed seekers ${ }^{3}$ in estimation, but they do not extend naturally to the type of simulation analysis of tax or welfare reform undertaken in this paper. For example, the classical selection-type method to control for fixed costs in estimation does so without explicitly evaluating the magnitude of the fixed cost. This is a drawback in simulation, where the fixed cost plays an important role in predicting the likelihood that a non-participating individual will move into employment in response to a policy reform. Although sole parents may face relatively low EMTR's (Beer (1998b) estimated that approximately $60 \%$ of all sole parents in Australia have zero EMTR's), their labour market choices are further complicated by the presence of potentially high fixed costs of employment (primarily due to childcare costs and other barriers to employment). The econometric approach must be sufficiently flexible to control effectively for such fixed costs.

These considerations lead us to model the employment choices of sole parents in Australia along the lines suggested by Keane and Moffitt (1997) and Van Soest (1995), where the hours choice set open to the individual is assumed to be finite. Their discrete approach to labour supply estimation has a number of advantages over continuous methods. Firstly, non-linear tax schedules are dealt with straightforwardly in estimation in a manner which does not force unreasonable restrictions on the parameters of the economic model. Secondly, unlike more standard Multinomial discrete choice methods applied in earlier work ${ }^{4}$, the preference model is fully structural and testable against economic theory. Thirdly, the Keane and Moffitt (1997) model may be extended to incorporate more recently developed

\footnotetext{
${ }^{1}$ Indeed, recent labour supply literature has suggested that the structure of the Hausman method biases predicted wage elasticities to a significant degree. See for example Mroz (1987) or Gourieroux, Laffont, and Montfort (1980)

${ }^{2}$ see Cogan (1981), Heckman (1979) among others.

${ }^{3}$ see Blundell, Ham, and Meghir (1987).

${ }^{4}$ See for example Duncan and Giles (1996).
} 
methods by Callan and Van Soest (1996) and Duncan and Giles (1998a) to control effectively for fixed costs in estimation. Indeed, the method used leads to an explicit imputation of the level of fixed costs. This is a particularly valuable extension given that the model is to be applied to simulation. Finally, we may feasibly incorporate random preference heterogeneity by applying Simulated Maximum Likelihood methods in estimation. The implementation of these methods of estimation requires detailed knowledge of the budget sets faced by sole parent families in Australia. In our empirical work we use the Melbourne Institute's Tax and Transfer Simulator (MITTS) to provide this information. ${ }^{5}$

The plan of the paper is as follows. The following Section provides a descriptive analysis of the employment choices among sole parents in Australia, looking in particular at the extent to which the system of taxes and government transfers are likely to influence those choices. In Section 3 we describe the basic structural discrete choice model, and how that model may be extended to differentiate among non-working households. Section 4 describes the empirical labour supply estimates, and Section 5 shows how this model may be applied to simulate the potential effects of (both actual and hypothetical) policy reforms on the employment choices among sole parents in Australia. In Section 6 we offer some concluding remarks.

\section{Employment and Incomes among Single Parent Households in Australia}

There are a number of elements in the Australian tax and transfer system which may potentially influence work incentives among those with low potential returns in the labour market. In common with most other developed countries, the structure of allowances, pensions and family payments in Australia combine to supplement incomes at low levels of earned income, at the cost of introducing high effective marginal tax rates over a potentially broad range of feasible hours choices. It is important to be clear about the likely direction of the employment incentives that such systems generate, and how changes to the tax and transfer system might lead to changes in the incentive to work. It is well known that a change to marginal tax rates has an ambiguous effect on the number of hours worked

\footnotetext{
${ }^{5}$ see Creedy and Duncan (1999).
} 
by those currently in work - the income and substitution effects of the change move in opposite directions. However, there has been little attempt to quantify the extent of these effects.

Single parent households are an interesting demographic group on which to focus, for a number of reasons. The presence of children in the household, and the fact that the sole parent is in the main the principal carer of those children, generates a tension between the need for income and the need (and desire) for the mother to spend time with her children. We tend therefore to see relatively flexible patterns of employment among sole parent households when measured against other comparable demographic groups. Around 45 per cent of the population of sole parents are in some form of paid employment. The fact that this figure is low when measured against employment rates over the wider population is an indication of the relative strength of barriers to employment, and potentially the different tastes for work, among sole parents. One also finds that those sole parents in employment are more likely to take advantage of part-time employment contracts, and therefore draw from a lower wage offer distribution than do other potential labour market entrants. In consequence, sole parents have become (in proportionate terms) one of the principal client groups for social assistance and family payment programs. They are therefore more likely to be affected by the adverse employment incentives that participation in such welfare programs tend inevitably to generate. The third figure below show the distribution of (weekly) hours among working single parent families in Australia, using data drawn from the Income Distribution Surveys (IDS) over the years 1994 to 1997 inclusive. Compared with the corresponding hours distribution of single males and single women, we can see that working sole parents do seem to have relatively flexible patterns of employment. There are nevertheless a number of spikes evident in the distribution of hours; these spikes (at 20 hours, and in the range of 38 to 40 hours) are most likely to have been caused by institutional constraints in the wage/hours contract offered to sole parents. 


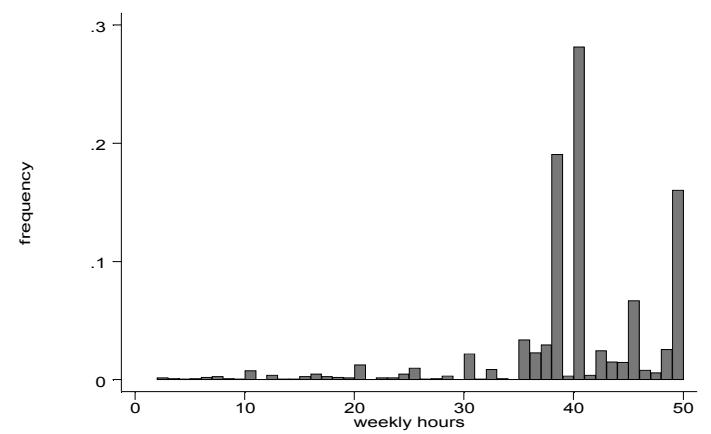

Hours distribution: single men

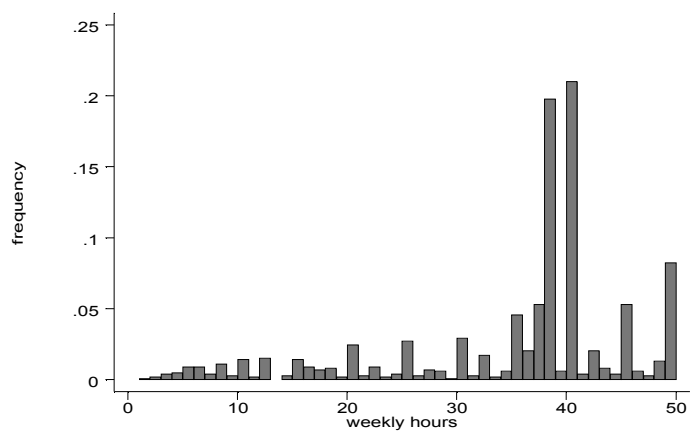

Hours distribution: single women

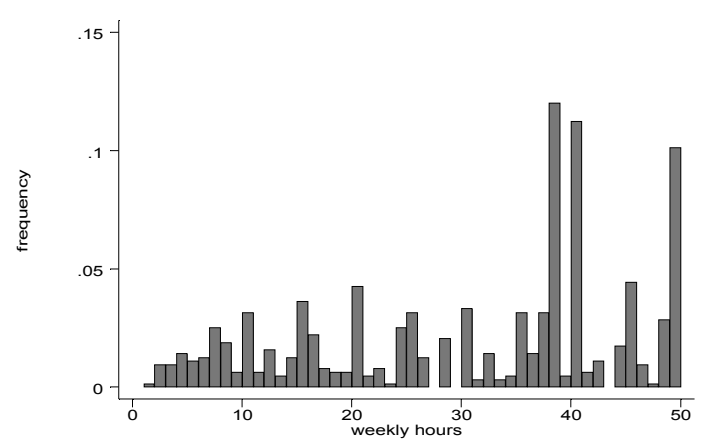

Hours distribution: single parents

There are many elements to the Australian tax and transfer system which combine to give highly non-linear EMTR schedules for most low-income or low-wage households. As an example, Figure 3.2 describes the budget constraint and EMTR schedules for a single parent with two dependent children aged 13, with a gross wage of Aus $\$ 20$ per hour (in July 1996 prices) and weekly rent of Aus $\$ 100 .{ }^{6}$ It is interesting to note from Figure 3.2 that, despite the apparent complexity of the Australian tax and transfer system (the lighter schedule in Figure 3.2), the overall appearance of the budget schedule is actually quite smooth. There are obviously local variations, but in general the Australian budget schedule (at least for a single parent family of the sort exemplified here) is characterised by marginal returns to work which generally diminish up to the point at which transfer payments are exhausted.

Using an algorithm introduced by Duncan and Stark (2000), one can derive average

\footnotetext{
${ }^{6}$ This is an actual individual on the IDS database, whose wage is imputed from personal characteristics. Calculations performed using MITTS. See Creedy and Duncan (1999) for details.
} 
Figure 2.1: hypothetical budget constraints among single parent households

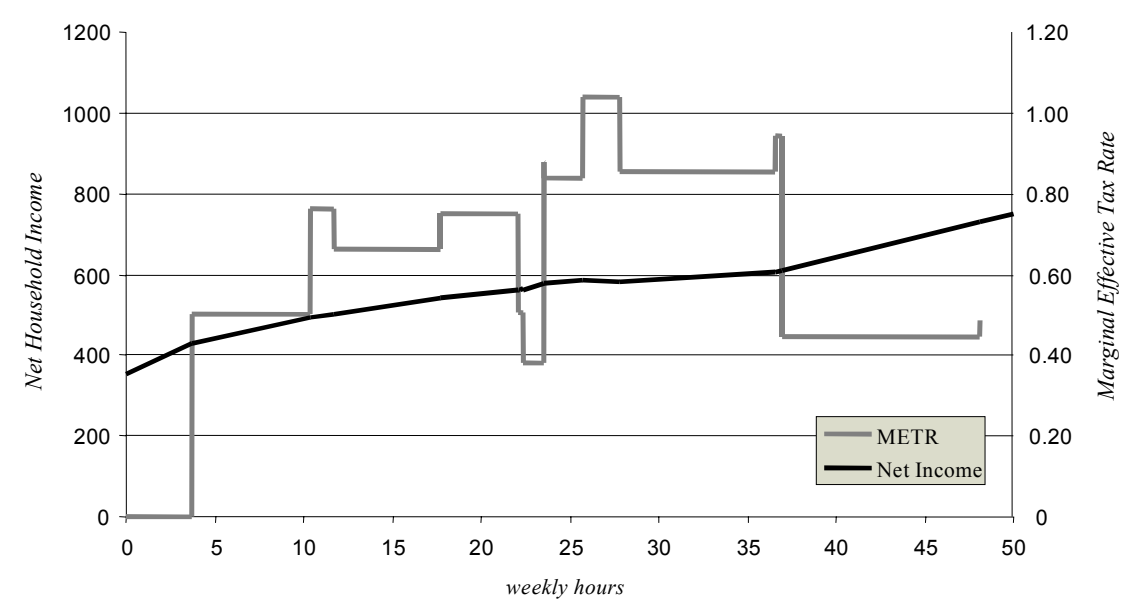

tax rate and replacement rate schedules over the full range of potential hours choices for a single parent with the characteristics described above. These schedules are shown in Figure 2.2, and are revealing to the extent that they highlight the potential disincentive effects associated with the Australian tax and transfer system ${ }^{7}$. The average tax rate (ATR) and replacement rate (RR) schedules are relatively smooth, and do not suffer too severely from rapid fluctuations as hours of work (or equivalently net income) are changed. For this particular case study, we see that replacement rates move smoothly from around $70 \%$ at 10 hours to around $50 \%$ at 40 hours.

To get a more general impression of the effects of the tax and transfer system in Australia on employment incentives, we need to move from single case studies to a wider distributional analysis. By evaluating eligibility of a large and representative sample of households to the range of allowance, pension and family payment programs available in Australia, we can move towards a more general understanding of the employment incentives faced by sole parents compared with other demographic groups. In Tables 2.1 and 2.2 we evaluate the distribution of effective marginal tax rates (EMTR's) and replacement rates for a sample of households drawn from the IDS. These statistics were generated by

\footnotetext{
${ }^{7}$ and can, more usefully, compare the potential work incentive effects associated with alternative tax and transfer systems.
} 
Figure 2.2: hypothetical tax rates among single parent households

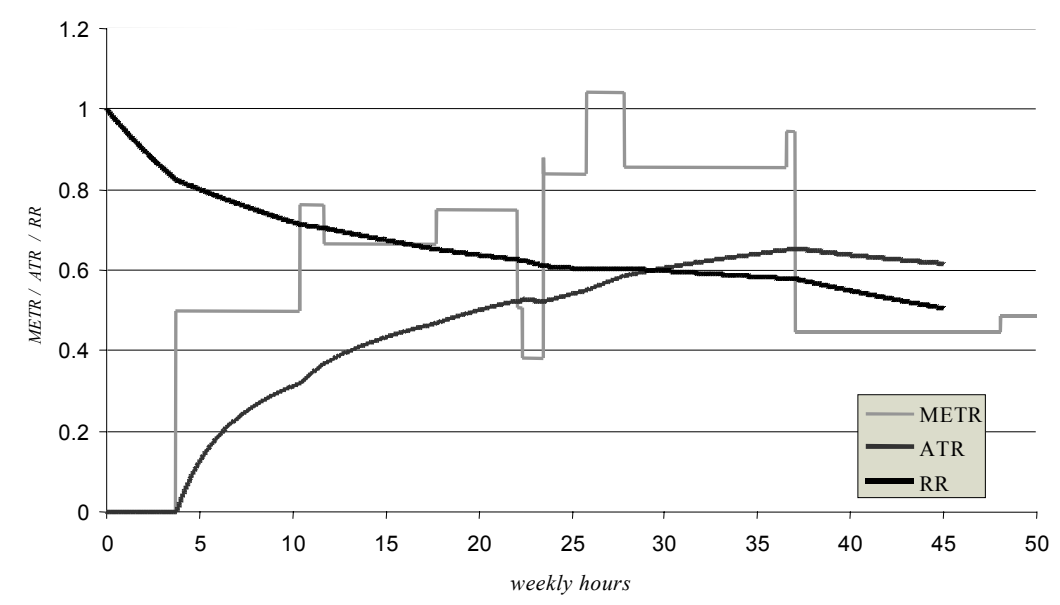

the Melbourne Institute's Tax and Transfer simulator (MITTS), using the tax and transfer system in place in January 2000. Effective marginal tax rates are evaluated at observed hours. We see a relatively high proportion of sole parent households on a zero EMTR, but these are all non-employed households whose instantaneous rate of withdrawal of social assistance payments is zero. For those in work, we find a broad range of potential EMTR's, some in excess of 100 per cent. In comparison with other groups, sole parent households are more likely to face high EMTR's in excess of 60 per cent.

Table 2.1: distribution of effective marginal tax rates: January 2000 tax system

\begin{tabular}{lrrrrrrrrrrrr}
\hline \hline & \multicolumn{1}{c}{ proportions with marginal effective tax rates in the range: } & \multicolumn{3}{c}{ Average } \\
& $0-10$ & $11-20$ & $21-30$ & $31-40$ & $41-50$ & $51-60$ & $61-70$ & $71-80$ & $81-90$ & $91-100$ & $>100$ & \\
\hline couple, no children & 48 & 1 & 4 & 17 & 22 & 1 & 1 & 2 & 0 & 0 & 3 \\
couple with children & 23 & 0 & 3 & 20 & 42 & 0 & 1 & 3 & 5 & 1 & 2 & 38.05 \\
single, no children & 45 & 2 & 5 & 26 & 14 & 0 & 1 & 2 & 2 & 4 & 0 & 24.83 \\
single parents & 59 & 0 & 0 & 5 & 16 & 0 & 7 & 4 & 5 & 1 & 2 & 24.88 \\
\hline
\end{tabular}

Our ultimate aim in this study is to move towards a full economic model of employment choices for sole parent households which take explicit account of the influence of taxes and 
Table 2.2: distribution of full-time replacement rates: January 2000 tax system

\begin{tabular}{lrrrrrrrrrrrrr}
\hline \hline & \multicolumn{1}{c}{ proportions with replacement rates in the range: } & \multicolumn{4}{c}{ Average } \\
& $0-10$ & $11-20$ & $21-30$ & $31-40$ & $41-50$ & $51-60$ & $61-70$ & $71-80$ & $81-90$ & $91-100$ & $>100$ \\
\hline couple, no children & 0 & 0 & 1 & 5 & 6 & 11 & 51 & 18 & 7 & 1 & 0 & 64.36 \\
couple with children & 0 & 0 & 0 & 2 & 3 & 6 & 17 & 35 & 33 & 3 & 0 & 73.97 \\
single, no children & 0 & 1 & 11 & 15 & 19 & 22 & 15 & 15 & 1 & 0 & 0 & 50.99 \\
single parents & 1 & 0 & 0 & 1 & 3 & 8 & 55 & 30 & 1 & 0 & 0 & 66.08 \\
\hline
\end{tabular}

transfers on the returns to employment. To do so requires that we place some structure on the labour supply decisions of sole parents, and this provides a point of departure for the remainder of the paper.

\section{An Economic Model of Labour Supply}

\subsection{Discrete versus Continuous Labour Supply}

The traditional approach to the modelling of labour supply maintains that the decision variable, hours of work, is continuous and unconstrained. Individuals are assumed to derive utility from net household income $Y$ (shared between current and future consumption) and leisure $L$. Let these preferences be represented by

$$
U=U(Y, L ; X)
$$

where $X$ represents individual characteristics. Behavioural decisions are constrained to lie within a budget set defined in terms of: gross wage rates $W$; total household income $V$ from assets and other unearned sources and; the tax system $T(H, W, V ; X)$, where $H=T-L$ for some time endowment $T$. This budget set takes the form

$$
Y=W H+V-T(H, W, V ; X)-F C\left(Z_{c}\right)
$$

where $T(H, W, V ; X)$ represents tax payments minus government transfers (assumed to depend on both earned income $W . H$ and unearned income $V$ and household characteristics $X)$ and $F C\left(Z_{c}\right)$, the fixed cost of employment for a parent with characteristics $Z_{c}$. For a 
continuous model of labour supply, the sole parent would maximise (3.1) subject to (3.2) over a continuum of hours. The solution to the following optimisation program

$$
\max _{H} U(Y, T-H) \text { s.t. } Y \leq W H+V-T(H, W, V ; X)-F C\left(Z_{c}\right) .
$$

would yield an expression for desired hours $H^{*}$, with the characteristics of this labour supply function depending both on the form for preferences (3.1) and the precise form of the tax function $T(. ;$.$) . Although it is relatively straightforward to derive optimal hours$ functions for a wide range of preference specifications ${ }^{8}$, the fundamental non-linearity of the tax function $T(. ;$.$) causes more difficulties both in derivation and estimation.$

There have been a number of responses among continuous studies of labour supply behaviour to the problem of dealing with a non-linear tax and transfer system. An early approach, proposed initially by Hall (1973), simply linearises the budget constraint around observed hours, as if the worker faces a linear budget constraint whose slope (and implicit intercept) is defined exclusively by the marginal rate at that hours point. A more recent approach developed initially by Burtless and Hausman $(1978)^{9}$, incorporates a fuller description of the budget constraint (rather than simply the observed marginal tax rate) into the sample likelihood used in estimation. The underlying economic model compares the maximum utility on each linear segment of the budget constraint with the utility to be gained from non-participation in order to determine the most desired supply of labour. A third approach is attributable to Flood and T.MaCurdy (1992) in the context of Sweden. Their technique exploits the progressivity of the Swedish tax system to approximate a piecewise budget constraint by a smooth, continuously differentiable function. However, each of these approaches to continuous estimation in the presence of non-linear taxes are problematic $^{10}$, and attention has increasingly turned towards labour supply models which use a discretised budget set, in which individuals are assumed to optimise over a finite set of hours choices. ${ }^{11}$

\footnotetext{
${ }^{8}$ see Stern (1986) for a useful survey.

${ }^{9}$ See also Arrufat and Zabalza (1986), Hausman (1980), Hausman (1985) and Moffitt (1986) inter alia.

${ }^{10}$ for reasons laid out variously in Blundell, Duncan, and Meghir (1992), Duncan and Giles (1996),

Gourieroux, Laffont, and Montfort (1980) and Mroz (1987)

${ }^{11}$ See, for example, Bingley and Walker (1997), Duncan and Giles (1996), Duncan and Weeks (1997), Keane (1995), Keane and Moffitt (1997), Van Van Soest (1995) and Duncan and Giles (1998b).
} 
Quite apart from the problem of coping with non-linearities in the tax schedule, the move from continuous to discrete modes of estimation is motivated by more fundamental empirical reasoning. Observed labour market behaviour takes the form of fixed wage-hours contracts, with individuals choosing from among a discrete set of hours combinations (most often at part-time levels of around 20 hours, and at full- time levels of between 38 and 40 hours per week). In particular, for prime-aged married men the effective labour supply decision is likely to be a work full-time/don't work one. A greater degree flexibility is generally afforded to sole parents, but there is evidence nevertheless of some constraints on the hours contracts available to them. A comparison of the hours distribution among working single men , single women and single parents (see the earlier distributional figures) supports this general contention, and emphasises in particular the essentially binary nature of the hours choice for single men and single (childless) women, compared with a more flexible labour supply choices made by (or imposed upon) single parents. ${ }^{12}$ To fail to deal with these institutional constraints in estimation can lead to problems of bias in the derived preference parameters. A discrete approach to the estimation of labour supply responses can provide one response to the problem of institutional constraints in employment choices.

The strategy adopted in the discrete approach is to replace the entire budget set with a finite number of points thereon, and allow the sole parent to optimise only over those discrete points. The procedure supposes that hours choices can be approximated by the discretised hours level $H_{(.)} \in\left\{H^{1}, H^{2}, . ., H^{P}\right\}$ according to the grouping rule

$$
\begin{aligned}
H_{(.)}= & H^{1} \quad \text { if } H \leq H_{1}^{B} \\
= & H^{2} \quad \text { if } H_{1}^{B}<H \leq H_{2}^{B} \\
& \ldots \ldots \ldots \ldots \ldots \\
= & H^{P-1} \text { if } H_{P-2}^{B}<H \leq H_{P-1}^{B} \\
= & H^{P} \quad \text { if } H>H_{P-1}^{B},
\end{aligned}
$$

\footnotetext{
${ }^{12}$ Among working single male households, there is a clear clustering of observations at the "usual" working week of 40-50 hours. For sole parents, there is some clustering around 40-50 hours per week, although we also see a greater dispersion across a wide range of hours.

The data on which these figures are based also forms the estimation sample in this study. More detail on the dataset is given later in the paper.
} 
giving $P$ alternative values for $H_{(.)} \cdot{ }^{13}$ Family net incomes may then be calculated for the set of discrete hours combinations $H_{(.)}$as

$$
Y\left[H_{(.)}\right]=W H_{(.)}+V-T\left(H_{(.)}, W, V ; X\right) \text { for } H_{(.)} \in\left\{H^{1}, H^{2}, . ., H^{P}\right\}
$$

\subsection{A Basic Structural Model}

In the basic discrete model of labour supply, the sole parent is assumed to maximise the preference function (3.1) over a discretized hours set $H_{(.)} \in\left\{H^{1}, H^{2}, . ., H^{P}\right\}$. That is, their preferred hours choice is assumed to derive from the outcome of an optimisation problem of the form

$$
\max _{H_{(.)} \in\left\{H^{1}, H^{2}, . ., H^{P}\right\}} U\left(Y\left[H_{(.)}\right], T-H_{(.)} ; X\right)
$$

for some preference specification $U($.$) , where Y\left[H_{(.)}\right]$represents the net income corresponding to each discrete hours alternative $H_{(.)}$. This approach removes from the optimisation problem many of the complexities of a nonlinear tax schedule, but at the cost of introducing rounding errors in the hours levels used for estimation. The degree of aggregation may therefore have a potentially detrimental effect on the reliability of the parameters estimated under a discrete regime, and ought at the very least to be subjected to sensitivity analysis. The structural discrete method is nevertheless parsimonious in its parameterisation of tastes, and preserves the same preference structure over the whole range of hours. ${ }^{14}$

\footnotetext{
${ }^{13}$ In the subsequent analysis we use the choice set $H_{(.)}=\{0,5,10,15,20,25,30,35,40,45,50\}$ where $H_{1}^{B}=2.5, H_{2}^{B}=7.5, H_{3}^{B}=12.5, H_{4}^{B}=17.5, H_{5}^{B}=22.5, H_{6}^{B}=27.5, H_{7}^{B}=32.5, H_{8}^{B}=37.5$, $H_{9}^{B}=42.5$ and $H_{9}^{B}=47.5$.

${ }^{14} \mathrm{~A}$ reduced form alternative to this discrete structural approach would separately parameterise the utility in each labour market state as a function of exogenous characteristics. Multinomial Probit or Logit methods of estimation would typically be employed for such a reduced form model. The drawback with this approach is principally the lack of parsimony in the parameterisation. For $k$ exogenous covariates and $P$ labour market states, one would have to estimate $k(P-1)$ parameters for a logit and up to $(P-1)[k+(P-2) / 2]$ parameters for a multinomial probit model with a full covariance structure. And the fact that the model is not obviously consistent with optimising behaviour makes it diffucult to interpret or rationalise the empirical results.
} 
Random disturbances specific to each labour market state are added to utilities in each state $H_{(.)} \in\left\{H^{1}, H^{2}, . ., H^{P}\right\}$, giving

$$
U_{H(.)}^{*}=U\left(T-H_{(.)}, Y_{H(.)} ; X\right)+\varepsilon_{H(.)} .
$$

The random terms $\varepsilon_{H(.)}$ for $H_{(.)} \in\left\{H^{1}, H^{2}, . ., H^{P}\right\}$ are assumed to be independently distributed as a Type I Extreme Value, yielding probabilities of choosing state $H_{(.)}=H^{j}$ which take the form

$$
\begin{aligned}
\operatorname{Pr}\left[H_{(.)}=H^{j} ; X\right]= & \operatorname{Pr}\left[U_{H^{j}}^{*}>U_{H^{p}}^{*} \text { for all } j \neq p, p \in\{1, . ., P\}\right] \\
= & \frac{\exp \left[U\left(T-H^{j}, Y_{H^{j}} ; X\right)\right]}{\sum_{k=1}^{P} \exp \left[U\left(T-H^{k}, Y_{H^{k}} ; X\right)\right]} .
\end{aligned}
$$

For the basic structural model, the likelihood contribution corresponding to (3.8) is

$$
L(\phi \mid X)=\sum_{j=1}^{P} d_{j} \ln \operatorname{Pr}\left[H_{(.)}=H \mid X\right]
$$

where $d_{j}=\mathbf{1}\left(H_{(.)}=H^{j}\right)$.

For the empirical analysis the quadratic direct utility function favoured by Keane and Moffitt (1997) and Duncan and Giles (1998b) is chosen, whereby

$$
U(H, Y)=\alpha_{y y} Y^{2}+\alpha_{h h} H^{2}+\alpha_{y h} Y H+\beta_{y} Y+\beta_{h} H
$$

for parameters $\phi=\left\{\alpha_{y y}, \alpha_{h h}, \alpha_{y h}, \beta_{y}, \beta_{h}\right\}$. This function is tractable, yet permits a wide range of possible behavioural responses. ${ }^{15}$ Observed heterogeneity is introduced linearly through parameters $\beta_{y}$ and $\beta_{h}$, such that

$$
\begin{aligned}
& \beta_{y}=\beta_{y 0}+\beta_{y 1}^{\prime} X \\
& \beta_{h}=\beta_{h 0}+\beta_{h 1}^{\prime} X
\end{aligned}
$$

for exogenous characteristics $X$. The characteristics we include in the empirical estimates include dummies for the age of the youngest child, age and education. One can additionally

\footnotetext{
${ }^{15}$ See Stern (1986) for an excellent discussion of the properties of this and other functions.
} 
include random preference terms to the basic specification. We choose to enter random preference terms through the linear utility parameters 3.9 and 3.10, giving

$$
\begin{aligned}
& \beta_{y}^{*}=\beta_{y 0}+\beta_{y 1}^{\prime} X+v_{y} \\
& \beta_{h}^{*}=\beta_{h 0}+\beta_{h 1}^{\prime} X+v_{h} .
\end{aligned}
$$

The stochastic preference terms $\left\{v_{y}, v_{h}\right\}$ are assumed jointly normal. Although now the likelihood function has no analytical closed form, estimation can be undertaken via the method of Simulated Maximum Likelihood. ${ }^{16}$

\subsection{Modelling Participation}

The participation decision is probably the hardest aspect of the labour supply decision to get right. Yet the work incentive impact at the point of participation is often the most important consideration when assessing the incentive and welfare impact of tax or benefit reform proposals; see Heckman (1993). For example, in the UK, the Family Credit system of in-work support has seen three relatively recent structural reforms, each of which has been designed with the objective of encouraging participation: see Duncan and Giles (1996). Empirical evidence suggests that the participation elasticity is large relative to conditional hours elasticities, suggesting a low reservation wage for many groups.

To suggest that all those who are observed not to be in paid employment do so through choice is unsustainable ${ }^{17}$. There are many reasons why one might observe individuals out of the labour market. Some individuals would prefer to be in employment, and are seeking work, but remain involuntarily unemployed on the basis either of their own human capital characteristics, or in the face of prevailing labour market conditions. Other potential participants are discouraged from seeking work as a result of search costs, or fixed costs of employment (principally the costs associated with the care of pre-school children should they return to work). These affect the likelihood that a potential worker moves into paid employment, and can be controlled for in estimation. Blundell, Ham, and Meghir (1987) discuss a likelihood-based approach which exploits sample information to

\footnotetext{
${ }^{16}$ See Hajivassiliou and Ruud (1994) or McFadden (1989) for a discussion of simulation methods of econometric estimation.

${ }^{17}$ See Mroz (1987) for empirical evidence in support of this claim.
} 
differentiate those who are unemployed but seeking work and those who are self-reported non-participants, and Cogan (1981) describes a method to control directly for fixed costs in estimation.

\subsection{1. unobserved wage rates}

In a typical sample survey of data on individual employment choices, it is typical not to observe wage rates among non-workers. This poses a problem when simulating behavioural responses, since the budget constraint over which a non-employed single parent is supposed to optimise will clearly depend on the hourly wage rate that she would command were she to enter paid employment. One common solution to this problem is to estimate the expected market wage rate received by individuals with a given set of observed characteristics. This conditional wage expectation may be used in place of missing data for non-workers when estimating econometric models of labour supply. ${ }^{18}$

\subsection{2. modelling non-participation}

Some sources of microdata identify the main reason why an individual is not in paid employment. Some people report that they are looking for work, some report that they want to work but are not looking (including those who cite the need to care for children as a reason for not looking), and some report that they do not want to work. This information can be used to differentiate individuals in estimation and simulation. Keane (1995) factors exogenous child-related and fixed costs of work into his estimation procedure, by netting from the household net income of working families a state-specific average fixed cost. Callan and Van Soest (1996) introduce a method by which fixed costs may directly be

\footnotetext{
${ }^{18}$ We estimate wage rates for the single parents in our sample using wage functions reported in Creedy, Duncan, Harris, and Scutella (2001). An alternative approach by Blundell, Duncan, McCrae, and Meghir (2000) integrates the model likelihood for non-workers over the range of a pre-estimated wage distribution. The practical implementation of this approach requires quadrature techniques whereby the potential net incomes of nonworkers are derived for a set of wage rates drawn from the pre-estimated conditional wage distribution. The likelihood is formed by averaging over this set of wage rates for each individual. The approach makes it possible to estimate the correlation of wages and the unobserved heterogeneity in individual utilities, but is computationally intensive.
} 
imputed in estimation. By attributing to those who want to work but do not look for work an unobserved shadow fixed cost, and parameterising this cost in terms of observable characteristics and a random element, they were able to estimate a 'shadow fixed cost' equation. This equation was used in microsimulation to eliminate the reservation wage condition most commonly applied as an explanation of non-participation. The advantage of the Callan-Van Soest approach is that the fixed cost imputation can be factored directly into either continuous or discrete behavioural microsimulation.

Duncan and Giles (1998b) implement the Callan-Van Soest method in an application to UK data. They analyse the potential labour market impact of the Working Families Tax Credit (WFTC) as a replacement for the UK Family Credit system of in-work benefit, concentrating on the likely effect on single parent families. They found that the imputation of fixed costs reduced significantly the inertia in discrete microsimulation that is typically found at the point of non-participation.

There are numerous observationally equivalent reasons as to why individuals may be observed to be not working. They may be: involuntary unemployed; not in the labour force or; a discourage worker. ${ }^{19}$ It is preferable to accommodate all of these states in model estimation. The data source we use in this study (the Income Distribution Survey) only enables us to identify three labour force states: employed; unemployed and; not in the labour force.

\subsection{3. introducing fixed costs in estimation}

In continuous studies, fixed costs of work are typically accommodated by modelling the participation and hours decisions separately using the selection-type models of Heckman (1979) (see Blundell, Duncan, and Meghir (1998) inter alia). Specifically, by including in the model of participation instruments which are thought to be correlated with fixed costs, one may control for the effects of fixed costs in estimation. This method is less appropriate when the model is to be extended to simulate the impact of tax or benefit reform on participation. Firstly, the statistical model of participation is typically unaffected by changes in tax parameters. And secondly, fixed costs of work are generally neither measured nor explicitly predicted. Hence, one cannot factor such costs into a comparison

\footnotetext{
${ }^{19}$ One could also consider a worker not working due to illness, although that is not considered here.
} 
of utility in and out of the labour market. In consequence, many microsimulation studies report a relative inertia in the propensity to move into work in response to tax or transfer reforms which ought in principle to improve work incentives.

In this study, we choose to follow Callan and Van Soest (1996) in which fixed costs are imputed directly. We exploit observed differences in labour market status among women who are largely homogeneous in the characteristics thought to influence tastes for work. By relating those observed differences to instruments which proxy fixed costs, any systematic relationships are picked up in the parameters of a "shadow" fixed cost equation of the form

$$
F C=X_{F C} \cdot \gamma+v_{f}
$$

where the unobserved fixed cost component $v_{f}$ is distributed normally around zero mean, and $X_{F C}$ are instruments which should be chosen to capture potential variations in fixed costs. The stochastic term $v_{f}$ may be correlated with the random preference parameters $\varepsilon_{Y}$ and $\varepsilon_{H}$.

Fixed costs are easily incorporated into estimation. As they only impact on workers, the utilities $U\left(T-H, Y_{H} ; X\right)$ entering the likelihood function of (3.7) now become $U(T-$ $\left.H, Y_{H}-F C ; X\right)$ for all states $H^{j}>0$. To observe a working single parent in the presence of fixed costs therefore requires that

$$
\max _{H_{(.)} \neq 0} U\left(T-H_{(.)}, Y_{H_{(.)}}-F C ; X\right)>U\left(Y_{0}, T ; X\right) \text {. }
$$

\section{Empirical Results}

\subsection{The Data}

The data used in this analysis is a pooled series of four Income Distribution Surveys (IDS's), made available through the Australian Bureau of Statistics, over the years 1994-95 to 1997-98. The survey collects information on the sources and amounts of income received by persons resident in private dwellings throughout Australia. It provides fairly explicit information on the characteristics of income units and persons surveyed, for example, information on individual, family and household incomes, labour market attachment, as well as standard personal demographics. The survey is continuous throughout the financial 
year, with around 650 households interviewed each month. We exclude self-employed and retired households from the estimation sample, along with any extreme outliers, missing values etc. This leaves a working sample of 2,063 sole parent households. To generate net incomes we the Melbourne Institute Tax and Transfer Simulator (MITTS). MITTS a micro-simulation model of the Australian tax and benefit system that calculates tax and medicare liabilities, allowance and pension entitlements and family payments for the four IDS years 1994 to 1997. The financial returns for each working age individual to employment at all possible hours are calculated using gross and net incomes at these levels. For the waged their current wage was assumed to remain unchanged, and for the unwaged, wages were imputed based on their personal characteristics. The use of MITTS allows us to generate highly accurate financial budget constraints for each individual in the sample.

\subsection{Model Estimates}

A range of estimates for the labour supply behaviour of sole parent households are report in Table 4.1. ${ }^{20}$ For this first series of estimates we choose a labour supply regime with eleven hours states in which the parents are allocated one hours level in the set $H_{(.)}=$ $\{0,5,10,15,20,25,30,35,40,45,50\}$ using the following allocation rule:

$$
\begin{aligned}
H_{(.)} & =0 \text { if } H \leq 2.5 \\
& =5 \text { if } 2.5<H \leq 7.5 \\
& =10 \text { if } 7.5<H \leq 12.5 \\
& =15 \text { if } 12.5<H \leq 17.5 \\
& =20 \text { if } 17.5<H \leq 22.5 \\
& =25 \text { if } 22.5<H \leq 27.5 \\
& =30 \text { if } 27.5<H \leq 32.5 \\
& =35 \text { if } 32.5<H \leq 37.5 \\
& =40 \text { if } 37.5<H \leq 42.5 \\
& =45 \text { if } 42.5<H \leq 47.5 \\
& =50 \text { if } H>47.5
\end{aligned}
$$

\footnotetext{
${ }^{20}$ Note that these are not time-invariant, and have been uprated to the year 2000 .
} 
The specifications are considered sequentially: the first model (1) is a simple specification in which we estimate a utility function with constant parameters (i.e. parameters which do not vary with observed characteristics). In the second model (2) we allow for observed heterogeneity to enter the linear and quadratic terms of the basic utility function parameters; in model (3) we add to the second specification a constant fixed cost term. The instruments chosen to account for variation in tastes for work include dummies for the age of the youngest child (0-2, 3-4 and 5-9) only for the quadratic terms and; additionally for the linear terms: the total number of children; whether the individual was aged 40 or over and; whether they possessed any post-compulsory educational qualifications.

In Table 4.2 the specification is further augmented to allow firstly for fixed costs to vary with a series of observed characteristics. The fifth specification (model 5) incorporates independent random preference heterogeneity, whereas model 6 allows for correlation among the random preference terms. The instruments chosen to allow for variation in fixed costs include a dummy for residing in a capital city, the number of pre- and school-aged children and a dummy for residing in New South Wales.

The specifications are considered sequentially: the first model (1) is a simple specification, in which the utility function is estimated with constant parameters (i.e., parameters which do not vary with observed characteristics). In the second model (2) we allow for observed heterogeneity to enter the linear and quadratic terms of the basic utility function parameters; in model (3) we add to the second specification a constant fixed cost term. The instruments chosen to account for variation in tastes for work include dummies for the age of the youngest child (0-2, 3-4 and 5-9) only for the quadratic terms and; additionally for the linear terms: the total number of children; whether the individual was aged 40 or over and; whether they possessed any post-compulsory educational qualifications.

For the simpler specifications, a formal Likelihood Ratio testing criterion clearly suggests the superiority of the more flexible functional form of model (2) over model (1) and also model (3) over model (2). This is despite the fact that the preferences parameters of this specification appear to have been estimated with less precision individually than for either model (1) or (2).

In the simplest specification, the coefficients on both the linear income and hours terms, and their squares, suggest increasing and diminishing marginal utility of income, and decreasing and diminishing marginal utility for hours worked, as expected. Introducing 
Table 4.1: Model Estimates - Utility Function only; Observed Heterogeniety and Constant Fixed Costs

\begin{tabular}{|c|c|c|c|c|c|c|}
\hline \multirow[b]{2}{*}{$\alpha_{Y Y} \times 100$} & \multicolumn{2}{|c|}{ (1) } & \multicolumn{2}{|r|}{$(2)$} & \multicolumn{2}{|c|}{ (3) } \\
\hline & -0.498 & $0.148^{* *}$ & -0.909 & $0.226^{* *}$ & -1.668 & $0.533^{* *}$ \\
\hline$\times 1($ youngest child $0-2)$ & - & - & 0.812 & $0.222^{* *}$ & -0.701 & 0.469 \\
\hline$\times 1($ youngest child $3-4)$ & - & - & 0.296 & 0.371 & 0.135 & 0.477 \\
\hline$\times 1($ youngest child $5-9)$ & - & - & 0.702 & $0.219^{* *}$ & 0.980 & $0.481^{* *}$ \\
\hline$\alpha_{H H} \times 100$ & 0.316 & $0.017^{* *}$ & 0.165 & $0.024^{* *}$ & -0.011 & 0.027 \\
\hline$\times 1($ youngest child $0-2)$ & - & - & 0.098 & $0.040^{* *}$ & 0.012 & 0.053 \\
\hline$\times 1($ youngest child $3-4)$ & - & - & -0.008 & 0.048 & -0.006 & 0.051 \\
\hline$\times 1($ youngest child $5-9)$ & - & - & -0.010 & 0.034 & 0.044 & 0.043 \\
\hline$\alpha_{Y H}$ & 1.050 & $0.185^{* *}$ & 2.542 & $0.307^{* *}$ & 0.511 & $0.240^{* *}$ \\
\hline$\beta_{Y}$ & 0.707 & $0.183^{* *}$ & 0.643 & $0.246^{* *}$ & 1.564 & $0.436^{* *}$ \\
\hline$\times 1($ youngest child $0-2)$ & - & - & -1.156 & $0.335^{* *}$ & 0.572 & 0.400 \\
\hline$\times 1($ youngest child $3-4)$ & - & - & -0.352 & 0.542 & -0.161 & 0.327 \\
\hline$\times 1($ youngest child 5-9) & - & - & -0.766 & $0.315^{* *}$ & -0.666 & $0.347^{*}$ \\
\hline \# children & - & - & -0.152 & $0.054^{* *}$ & 0.183 & $0.064^{* *}$ \\
\hline$\times 1$ aged over 40 & - & - & -0.074 & 0.096 & -0.205 & $0.089^{* *}$ \\
\hline$\times 1$ qualification & - & - & 0.256 & $0.083^{* *}$ & 0.069 & 0.071 \\
\hline$\beta_{H}$ & -0.261 & $0.012^{* *}$ & -0.227 & $0.016^{* *}$ & -0.036 & $0.021^{*}$ \\
\hline ×1 (youngest child 0-2) & - & - & -0.055 & $0.026^{* *}$ & -0.033 & 0.024 \\
\hline$\times 1($ youngest child $3-4)$ & - & - & -0.011 & 0.033 & -0.017 & 0.023 \\
\hline ×1 (youngest child 5-9) & - & - & -0.002 & 0.022 & -0.033 & $0.020^{*}$ \\
\hline \# children & - & - & -0.008 & $0.004^{* *}$ & -0.009 & $0.002^{* *}$ \\
\hline$\times 1$ aged over 40 & - & - & 0.013 & $0.006^{* *}$ & 0.005 & 0.004 \\
\hline$\times 1$ qualification & - & - & 0.007 & 0.006 & 0.020 & $0.003^{* *}$ \\
\hline Fixed Costs/100 & - & - & - & - & 2.880 & $0.480^{* *}$ \\
\hline Log-Likelihood & $-5,525$ & & $-5,377$ & & $-5,073$ & \\
\hline Likelihood Ratio Test, $\chi_{d f}^{2}$ & & & (2) vs (1) & $296(d f=18)$ & (3) vs (2) & $608(d f=1)$ \\
\hline
\end{tabular}


Table 4.2: Model Estimates - Controlling for Fixed Costs and Random Preference Heterogeneity

\begin{tabular}{|c|c|c|c|c|c|c|}
\hline \multirow[b]{2}{*}{$\alpha_{Y Y} \times 100$} & \multicolumn{2}{|c|}{$(4)$} & \multicolumn{2}{|c|}{$(5)$} & \multicolumn{2}{|c|}{$(6)$} \\
\hline & -1.617 & 1.212 & -1.320 & $0.300^{* *}$ & -1.483 & $0.356^{* *}$ \\
\hline$\times 1($ youngest child $0-2)$ & -1.631 & 1.290 & -2.779 & $0.922^{* *}$ & -2.640 & $0.782^{* *}$ \\
\hline$\times 1($ youngest child $3-4)$ & -0.305 & 1.115 & -0.790 & 0.592 & -0.728 & 0.556 \\
\hline$\times 1($ youngest child $5-9)$ & 0.946 & 1.020 & 0.601 & $0.363^{*}$ & 0.650 & $0.378^{*}$ \\
\hline$\alpha_{H H} \times 100$ & -0.018 & 0.033 & -0.064 & $0.030^{* *}$ & -0.039 & 0.030 \\
\hline$\times 1($ youngest child $0-2)$ & 0.054 & 0.062 & 0.093 & $0.057^{*}$ & 0.105 & $0.057^{*}$ \\
\hline$\times 1($ youngest child $3-4)$ & 0.037 & 0.063 & 0.033 & 0.055 & 0.041 & 0.053 \\
\hline$\times 1($ youngest child $5-9)$ & 0.049 & 0.043 & 0.061 & 0.044 & 0.056 & 0.042 \\
\hline$\alpha_{Y H}$ & 0.473 & 0.350 & -0.309 & 0.421 & -0.280 & 0.396 \\
\hline$\beta_{Y}$ & 1.458 & 0.920 & 1.895 & $0.345^{* *}$ & 2.253 & $0.404^{* *}$ \\
\hline$\times 1($ youngest child $0-2)$ & 1.778 & 1.415 & 2.403 & $0.887^{* *}$ & 2.247 & $0.731^{* *}$ \\
\hline$\times 1($ youngest child $3-4)$ & 0.544 & 1.137 & 0.829 & 0.585 & 0.698 & 0.529 \\
\hline$\times 1($ youngest child $5-9)$ & -0.618 & 0.692 & -0.587 & $0.271^{* *}$ & -0.629 & $0.307^{* *}$ \\
\hline \# children & 0.187 & 0.121 & 0.198 & $0.069^{* *}$ & 0.246 & $0.081^{* *}$ \\
\hline$\times 1$ aged over 40 & -0.211 & $0.118^{*}$ & -0.270 & $0.106^{* *}$ & -0.325 & $0.129^{* *}$ \\
\hline$\times 1$ qualification & 0.102 & 0.078 & 0.109 & 0.103 & 0.050 & 0.118 \\
\hline$\beta_{H}$ & -0.029 & 0.037 & 0.011 & 0.018 & -0.019 & 0.019 \\
\hline$\times 1($ youngest child $0-2)$ & -0.075 & 0.048 & -0.099 & $0.031^{* *}$ & -0.100 & $0.029^{* *}$ \\
\hline$\times 1($ youngest child $3-4)$ & -0.056 & 0.047 & -0.063 & $0.030^{* *}$ & -0.061 & $0.027^{* *}$ \\
\hline$\times 1($ youngest child $5-9)$ & -0.037 & $0.020^{*}$ & -0.046 & $0.020^{* *}$ & -0.043 & $0.018^{* *}$ \\
\hline \# children & -0.009 & $0.003^{* *}$ & -0.005 & $0.003^{*}$ & -0.006 & $0.003^{* *}$ \\
\hline$\times 1$ aged over 40 & 0.005 & 0.004 & 0.003 & 0.004 & 0.006 & 0.004 \\
\hline$\times 1$ qualification & 0.021 & $0.004^{* *}$ & 0.020 & $0.003^{* *}$ & 0.019 & $0.004^{* *}$ \\
\hline Fixed Costs/100 & 2.985 & $1.105^{* *}$ & 2.899 & $0.238^{* *}$ & 2.481 & $0.250^{* *}$ \\
\hline$\times 1$ capital city & 0.020 & 0.087 & 0.035 & 0.072 & 0.038 & 0.065 \\
\hline \# pre-school children & -0.848 & 1.193 & -0.907 & $0.352^{* *}$ & -0.630 & $0.234^{* *}$ \\
\hline \# school aged children & -0.092 & 0.168 & -0.189 & 0.128 & -0.195 & $0.107^{*}$ \\
\hline$\times 1$ New South Wales & 0.382 & $0.100^{* *}$ & 0.327 & $0.097^{* *}$ & 0.287 & $0.088^{* *}$ \\
\hline$\sigma_{Y}^{2}$ & - & - & 0.651 & $0.308^{* *}$ & 1.418 & $0.579^{* *}$ \\
\hline$\sigma_{H}^{2}$ & - & - & 0.000 & 0.000 & 0.001 & 0.001 \\
\hline$\sigma_{F C}^{2}$ & - & - & 0.003 & 0.007 & 0.092 & $0.046^{* *}$ \\
\hline$\sigma_{Y, H}$ & - & - & - & - & -0.033 & $0.017^{*}$ \\
\hline$\sigma_{Y, F C}$ & - & - & - & - & -0.353 & $0.110^{* *}$ \\
\hline$\sigma_{H, F C}$ & - & - & - & - & 0.008 & $0.004^{* *}$ \\
\hline Log-Likelihood & $-5,063$ & & $-5,050$ & & $-5,045$ & \\
\hline Likelihood Ratio Test, $\chi_{d f}^{2}$ & (4) vs (3) & $20(d f=4)$ & (5) vs (4) & $25(d f=3)$ & (6) vs (5) & $12(d f=3)$ \\
\hline
\end{tabular}


observed heterogeneity (model 2), suggests that the marginal disutility of hours worked is greatest when the youngest child is very young (0-2), and lessens as the youngest child ages. The total number of children again increases the marginal disutility of work, although those single parents over 40 years of age are less averse to the number of hours worked. In terms of the parameters on squared hours, only the youngest child being 0-2 years of age, appears to exert any affect. With regard to income, the reference group, with youngest child over 10 years of age, appear to exhibit the strongest marginal utility of income, and the number of children rises, so this marginal utility of income falls. Age appears uninfluential, whereas the more highly educated have a higher marginal utility of income. Both the presence of the youngest child being 0-2 and 5-9, have a positive effect on the square of the income term.

When fixed costs are introduced, this appears to absorb the effect of previously significant variables. Of the significant variables, their affects appear to be consistent with those obtained from model (2). The model predicts an average (shadow) fixed costs of around $\$ 290$ pw.

In Table 4.2 the specification is further augmented to allow firstly for fixed costs to vary with a series of observed characteristics. The fifth specification (model 5) incorporates independent random preference heterogeneity, whereas model 6 allows for correlation among the random preference terms. The instruments chosen to allow for variation in fixed costs include a dummy for residing in a capital city, the number of pre- and school-aged children and a dummy for residing in New South Wales.

The introduction of variable fixed costs in model 4 (Table 4.2), again appears to be an improvement on the basis of the Likelihood Ratio criterion. Average (shadow) fixed costs are now estimated to be around $\$ 220 \mathrm{pw}$, as opposed to around $\$ 280$. It also suggests that there is a significant increase in fixed costs arising from living in N.S.W. (although interestingly, the effect of the number of children on fixed costs appears to be imprecisely estimated).

The addition of random preference heterogeneity terms (model 5) appears further to improve the specification of the model. We find some improvement in the overall fit of the model, and in the precision of the preference parameters. Finally, when fully unrestricted random preference heterogeneity is included, the model fit and precision of the preference parameters improves further. Average (shadow) fixed costs are now estimated to be around 
$\$ 230$ pw, and significantly higher in New South Wales. Those sole parents with younger youngest children, have a greater marginal disutilty of hours worked, as do the less formally educated. On the other hand, those with younger children tend to have a higher marginal utility of income, as would be expected. Older sole parents tend to exhibit a smaller marginal utility of income. In terms of the squared preference terms, those on hours squared remain imprecisely estimated, whilst only the youngest child being aged 0-2 has an effect on the squared hours term. Overall, however, there is little difference between the preference parameters of the most general specification (model 6) and the model with variable fixed costs but no random preference heterogeneity (model 4).

\subsection{Some Model Evaluations}

Given the complexities of the model specifications involved, it is not obvious how one might evaluate and interpret the above results. One attractive option is to consider how well the model predicts the distribution of hours choices, compared with the observed hours distribution. To do this, we use the parameters of each model in our series (1) to (5) to predict the probability of an individual being in a particular state. One simple approach is to allocate each individual to that outcome which yields the maximum probability. Comparing these predictions with the actual states yields the so-called "Hit and Miss" tables which are familiar in more standard discrete choice models. However, if standard techniques are used to do this (i.e., those based on the maximum probability rule stated above), such discrete choice models generally tend to heavily over-predict the empirically most frequently chosen outcome. This result stems from the fact that the random elements of the model are explicitly ignored in its subsequent evaluation.

An alternative method of evaluating such models, is to utilise the underlying economic model (in this instance, equation (3.5)) and to simulate it by repeated draws of the unobserved random variates. That is, it is necessary to draw from a Type I Extreme Value distribution. For each random draw, the probabilistic expressions are evaluated and the outcome which yields the maximum probability, is the one predicted for that repetition. Each separate hit and miss table is collected, and the simulated hit and miss table is simply the average of all of these independent ones. The results of this are presented in Table 4.3 for all of the model specifications. 
Table 4.3: Percentage Model Predictions (based on 1,000 random draws)

Predicted

\begin{tabular}{rccccccc} 
& Actual & $(1)$ & $(2)$ & $(3)$ & $(4)$ & $(5)$ & $(6)$ \\
\hline$H \leq 2.5$ & 58.3 & 39.9 & 41.9 & 53.6 & 53.5 & 55.1 & 59.0 \\
$2.5<H \leq 7.5$ & 3.0 & 17.6 & 15.6 & 3.3 & 3.3 & 1.8 & 1.9 \\
$7.5<H \leq 12.5$ & 3.3 & 8.5 & 7.8 & 3.8 & 3.8 & 2.9 & 2.9 \\
$12.5<H \leq 17.5$ & 2.9 & 4.7 & 4.7 & 4.0 & 4.0 & 3.4 & 3.2 \\
$17.5<H \leq 22.5$ & 3.5 & 3.1 & 3.3 & 4.3 & 4.2 & 3.9 & 3.6 \\
$22.5<H \leq 27.5$ & 2.7 & 2.4 & 2.7 & 4.4 & 4.4 & 4.4 & 4.0 \\
$27.5<H \leq 32.5$ & 2.9 & 2.3 & 2.6 & 4.6 & 4.6 & 4.9 & 4.3 \\
$32.5<H \leq 37.5$ & 4.7 & 2.5 & 2.8 & 4.9 & 4.9 & 5.3 & 4.6 \\
$37.5<H \leq 42.5$ & 11.6 & 3.3 & 3.5 & 5.2 & 5.2 & 5.8 & 5.1 \\
$42.5<H \leq 47.5$ & 2.7 & 5.3 & 5.3 & 5.7 & 5.7 & 6.1 & 5.5 \\
$H>47.5$ & 4.5 & 10.3 & 9.8 & 6.3 & 6.3 & 6.3 & 5.9 \\
$\%$ Correctly Predicted & & & & & & & \\
\hline
\end{tabular}


As Table 4.3 illustrates, the models which allow for varying fixed costs (models 4 to 6 ), clearly predict better than those which do not (1 to 3 ). The main reason for this is that if one ignores the fixed costs of employment, one is likely severely to underestimate the probability of working zero hours and overestimate the probability of working few hours. One can see this from the marked reduction in the probability of working fewer than 12 hours once fixed costs are introduced into the specification. As indicated by the Likelihood ratio tests, the performance of models 4 to 6 is very close, both being marginally more accurate than model 3 which assumes constant fixed costs.

To evaluate the economic coherence of our estimated model of preferences, we impute predicted indifference curves maps from the model estimates for a range of demographics. This is undertaken in Figures 4.4 and 4.5. The different demographics reveal variations in the amount of curvature in the corresponding indifference maps, but all are consistent with economic theory, increasing with hours of work and generally being concave over the feasible range of hours and income levels.

For both qualified and unqualified single parents with a single child, the indifference curve surfaces are at their steepest when the child is between 3 and 4 years of age. This implies that the parent's wage elasticities are at their lowest when their only child is at this age.

\section{Simulating Employment Responses to Policy Reform}

The model of preferences estimated in the previous section may be used to simulate the potential impact of tax or welfare policy reform on participation and hours choices among sole parent households. The principal which underpins this microsimulation approach is relatively straightforward and attractive; the practical implementation less so. The basic idea in behavioural microsimulation is to bring the estimated preference function for sole parent households (which varies by observed demographic characteristics) together with a detailed description of the net incomes which would be enjoyed at each possible hours alternative. By doing so, we arrive at an optimal employment choice under some benchmark tax system. We then introduce a new tax system following some policy reform. This alters the budget constraint, and therefore potentially alters the optimal choice of hours following the policy reform. By comparing the simulated employment optima for a 
Table 4.4: Predicted Indifference Curves: Parent under 40, with Qualification and One Child
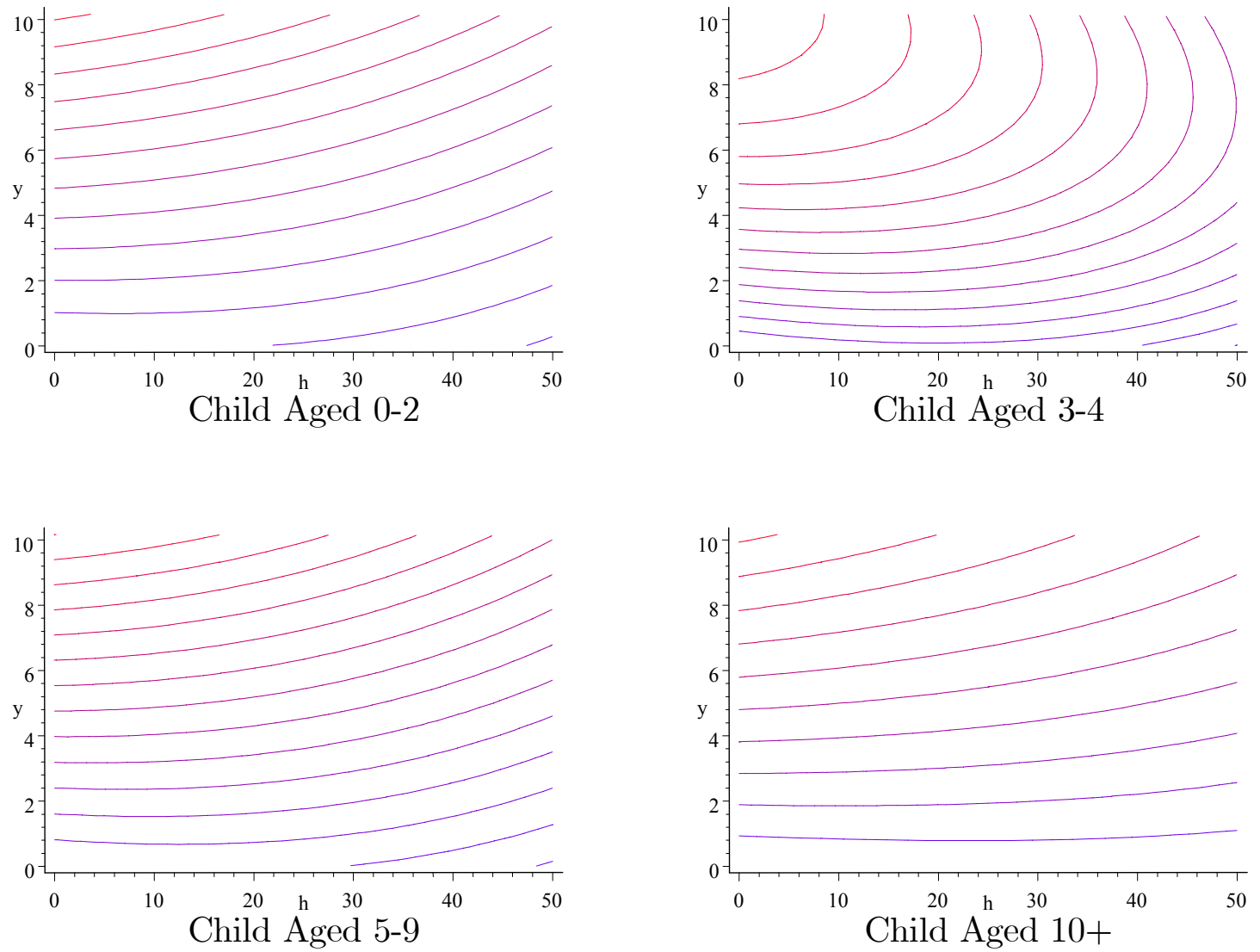
Table 4.5: Predicted Indifference Curves: Parent under 40, with No Qualification and One Child
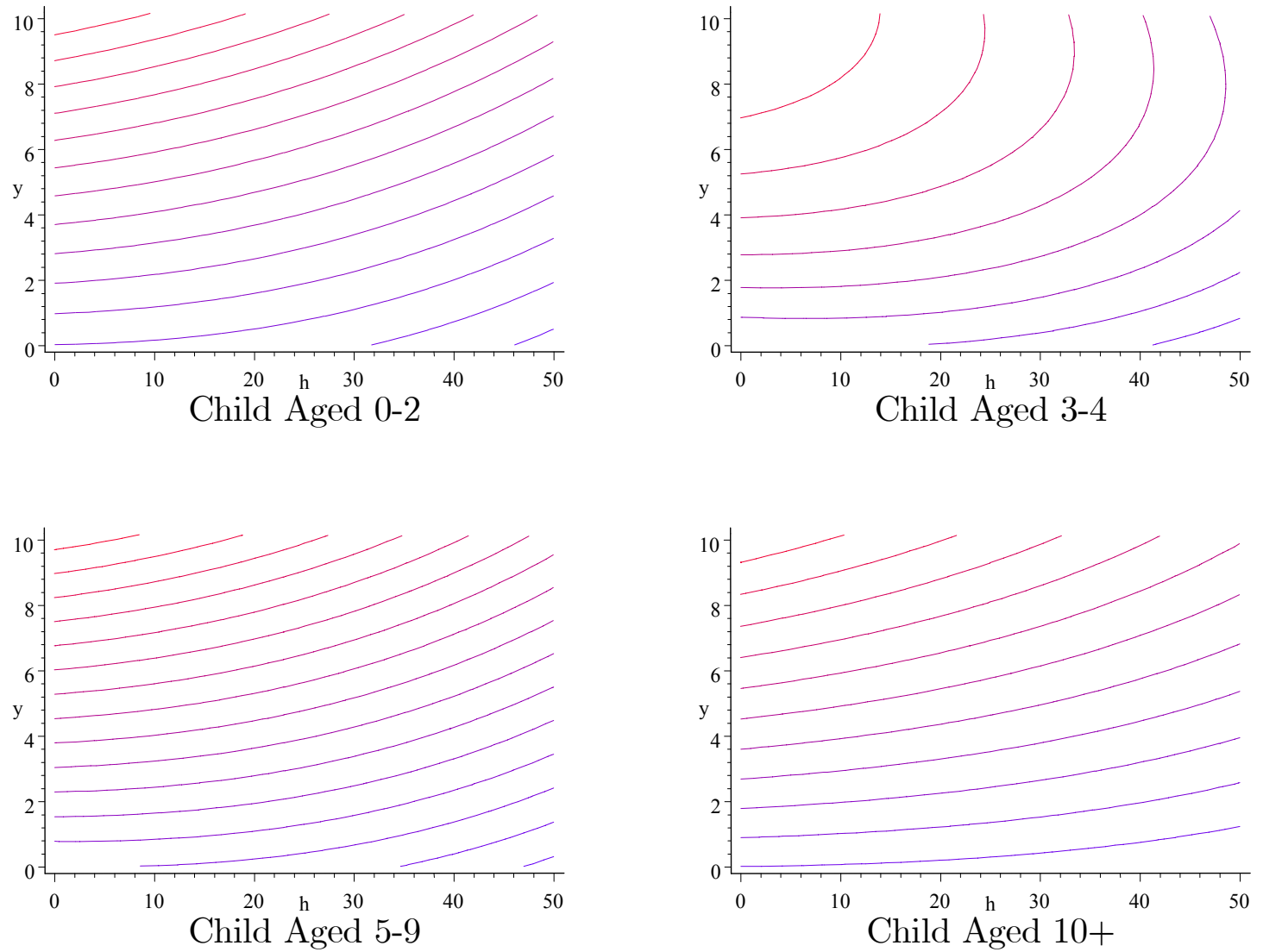
large and representative sample of sole parent households, we are able to build a pattern of employment transitions which indicate both the direction and degree of behavioural response to the tax reform.

For a discrete choice model of labour market status of the form described in (3.6) there is inevitably less accuracy both in the budget constraint information brought to bear in estimation and in the microsimulated hours responses to tax policy reform. Specifically, hours responses are limited in accuracy to the number of discrete hours bands into which the simulation sample is divided, and to the nominal value for hours of work allocated to observations falling within each band. Whilst this may be entirely appropriate for certain demographic groups (for example, married male workers) and certain tax reforms, it is by no means a universally acceptable feature. We know, for example, that the labour market decisions of sole parent households are relatively marginal or flexible, reflecting the high value such households place on non-work time.

The methods by which discrete models of labour market status are applied to discrete microsimulation are to a degree under-developed. One approach is to restrict attention to aggregated groups in the simulation sample and to summarise probabilities of occupation of each discrete state before and after some policy reform. This tends to conceal the impact of reform at the individual level, making it difficult to assess how the behaviourally-adjusted cost of the reform might be judged, and what might be the impact of a reform targeted either at a specific demographic group or over a specific range of hours. ${ }^{21}$ If one requires simulated responses at the level of the individual, on the other hand, it is not immediately obvious which is the most appropriate strategy to adopt.

A better strategy is to respect the probabilistic form of the discrete model by basing the behavioural simulation directly on predicted probabilities of transition from one labour market state to another. These transitions probabilities are hard to derive analytically for discrete models with more than three labour market states. For our application, we choose to apply re-sampling methods to generate probabilistic estimates of employment transitions. We do so by

1. drawing repeated realisations of the stochastic elements of the discrete choice model

\footnotetext{
${ }^{21}$ One might think, for example, of a reform to in-work support along the lines of the US EITC (see Sholz (1996)) or the new WFTC in the UK (see HM Treasury (1998)).
} 
(which requires a series of draws from Type I Extreme Value and Multivariate Normal Distributions for, respectively, state specific errors and random taste parameters);

2. applying the so-called 'maximum probability' rule to allocate each individual to the most probable state following each random draw; and

3. averaging these re-sampled transitions frequencies to arrive at simulated transitions probabilities.

\section{1. employment effects of policy reform: some specific examples}

To illustrate how our model can be applied to simulate the potential employment impact of tax or welfare reform in Australia, we consider the employment response of sole parent households to a range of policy reforms to the January 2000 tax system in Australia. Some reforms have actually taken place; others are entirely hypothetical, and are chosen merely to illustrate the potential of behavioural microsimulation to inform the policy debate. Four reforms in particular are considered;

- Reform 1: reduce the Single Parent Pension withdrawal taper from $50 \%$ to $40 \%$;

- Reform 2: reduce the withdrawal tapers for Family Payment from $50 \%$ to $30 \%$ (for the Basic payment) and from $100 \%$ to $30 \%$ (for higher payments);

- Reform 3: abolish the Single Parent tax rebate;

- Reform 4: increase the standard rate of income tax from $20 \%$ to $30 \%$.

Tables 5.1 and 5.2 evaluate the impact of these reforms in terms of employment responses, and Table 5.3 indicates the extent to which these hours responses act to modify the anticipated cost to the government of the policy reform (note that two columns are presented: static evaluates the results without taking into account behavioural responses, whereas $a d j$. does take these into account). 
Table 5.1: Simulated Employment Effects of Policy Reforms

\begin{tabular}{lrrrr}
\hline \hline & \multicolumn{4}{c}{ Behavioural responses to policy reforms (\%) } \\
\cline { 2 - 5 } & Reform 1 & Reform 2 & Reform 3 & Reform 4 \\
\hline non-work->work (\%) & 2.46 & 0.36 & - & 0.21 \\
work->non-work (\%) & - & - & 4.05 & 3.02 \\
workers working more & 0.17 & 0.22 & 0.41 & 0.31 \\
workers working less & 0.82 & 0.28 & 0.27 & 0.85 \\
average hours change & 0.55 & 0.15 & -1.22 & -1.24 \\
& & & & \\
\hline cost change (static,\%) & 1.25 & 1.04 & -4.33 & -1.74 \\
cost change (behavioural,\%) & 0.60 & 0.48 & 0.46 & 4.05 \\
\hline
\end{tabular}

\subsubsection{Reform 1: reduce the Single Parent Pension withdrawal taper from $50 \%$ to $40 \%$}

This reform was implemented in July 2000, and has the effect of increasing incomes from the Single Parent Pension for those working mothers who were either on partial Single Parent Pension (SPP), or worked to a point which just disqualified them from receiving any SPP. The reform makes part-time employment relatively more attractive, and has the potential to induce employment responses which might alter the expected costs to the government.

Table 5.1 summarises the simulated employment responses among the sample of sole parent households. We take the January 2000 tax and transfer system as our benchmark, and so uprate all data to January 2000 prices. Following the reduction in the SPP withdrawal taper, we simulate a set of transitions probabilities from one hours level to another using the methods described in the previous section. On average, the SPP reform was found to increase the participation rate of single parent households by around 2.5 per cent. The model simulates some movement in hours among working single parents, principally among full-time employees who might take advantage of the increased generosity of SPP at part-time hours levels by reducing their labour supply (see Table 5.1, panel 1). Interestingly, these behavioural responses act to reduce the net cost of the SPP reform to the government, at least in respect of sole parent households. Since more sole parents are modelled to work following the reform, income tax revenues increase while allowance and 
Table 5.2: Simulated Employment Transitions following Policy Reforms

\begin{tabular}{lrrrrrrrrr}
\hline \multicolumn{1}{l}{ Reform 1: reduce Single Parent Pension withdrawal taper from 50\% to $40 \%$} \\
\cline { 5 - 10 } hours & before & after & difference & 0 & $1-10$ & $11-20$ & $21-30$ & $31-40$ & $>40$ \\
0 & 58.9 & 56.4 & -2.5 & $\mathbf{5 6 . 4}$ & 0.1 & 0.6 & 0.9 & 0.6 & 0.2 \\
$1-10$ & 6.5 & 6.6 & 0.1 & - & $\mathbf{6 . 4}$ & - & - & - & - \\
$11-20$ & 6.7 & 7.7 & 1.0 & - & - & $\mathbf{6 . 7}$ & - & - & - \\
$21-30$ & 5.6 & 6.9 & 1.3 & - & - & - & $\mathbf{5 . 6}$ & - & - \\
$31-40$ & 15.7 & 15.8 & 0.1 & - & 0.1 & 0.2 & 0.1 & $\mathbf{1 5 . 1}$ & - \\
$>40$ & 6.5 & 6.6 & 0.1 & - & - & 0.1 & 0.1 & - & $\mathbf{6 . 3}$
\end{tabular}

Reform 2: reduce Family Payment tapers (50\% to $30 \%$ basic, \&100\% to 30\%)

\begin{tabular}{lrrrrrrrrr}
\hline & & & \multicolumn{5}{c}{ post-reform hours range } \\
\cline { 5 - 9 } hours & before & after & difference & 0 & $1-10$ & $11-20$ & $21-30$ & $31-40$ & $>40$ \\
0 & 58.9 & 58.6 & -0.3 & $\mathbf{5 8 . 6}$ & - & - & - & 0.1 & 0.2 \\
$1-10$ & 6.4 & 6.4 & 0 & - & $\mathbf{6 . 4}$ & - & - & - & - \\
$11-20$ & 6.8 & 6.7 & -0.1 & - & - & $\mathbf{6 . 7}$ & - & - & - \\
$21-30$ & 5.6 & 5.8 & 0.2 & - & - & - & $\mathbf{5 . 6}$ & - & - \\
$31-40$ & 15.6 & 15.8 & 0.2 & - & - & - & 0.1 & $\mathbf{1 5 . 5}$ & - \\
$>40$ & 6.6 & 6.7 & 0.1 & - & - & - & - & - & $\mathbf{6 . 4}$
\end{tabular}

Reform 3: abolish Single Parent Rebate

\begin{tabular}{lrrrrrrrrr}
\hline & & & \multicolumn{5}{c}{ post-reform hours range } \\
\cline { 5 - 9 } hours & before & after & difference & 0 & $1-10$ & $11-20$ & $21-30$ & $31-40$ & $>40$ \\
0 & 58.9 & 63 & 4.1 & $\mathbf{5 8 . 9}$ & - & - & - & - & - \\
$1-10$ & 6.4 & 6.2 & -0.2 & 0.4 & $\mathbf{5 . 9}$ & - & - & - & - \\
$11-20$ & 6.8 & 5.7 & -1.1 & 0.9 & - & $\mathbf{5 . 7}$ & - & - & - \\
$21-30$ & 5.6 & 5.0 & -0.6 & 0.5 & - & - & $\mathbf{5 . 0}$ & - & - \\
$31-40$ & 15.6 & 14.1 & -1.5 & 1.5 & 0.1 & - & - & $\mathbf{1 3 . 9}$ & 0.1 \\
$>40$ & 6.6 & 6.1 & -0.5 & 0.6 & - & - & - & - & $\mathbf{5 . 9}$ \\
\hline
\end{tabular}

Reform 4: increase basic Income Tax rate from $20 \%$ to $30 \%$

\begin{tabular}{lrrrrrrrrr}
\hline & & & \multicolumn{6}{c}{ post-reform hours range } \\
\cline { 5 - 9 } hours & before & after & difference & 0 & $1-10$ & $11-20$ & $21-30$ & $31-40$ & $>40$ \\
0 & 58.9 & 61.8 & 2.9 & $\mathbf{5 8 . 7}$ & 0.2 & - & - & - & - \\
$1-10$ & 6.4 & 7.1 & 0.7 & 0.1 & $\mathbf{6 . 4}$ & - & - & - & - \\
$11-20$ & 6.8 & 6.5 & -0.3 & 0.3 & - & $\mathbf{6 . 3}$ & - & - & - \\
$21-30$ & 5.6 & 5.3 & -0.3 & 0.4 & - & - & $\mathbf{5 . 1}$ & - & - \\
$31-40$ & 15.6 & 13.5 & -2.1 & 1.6 & 0.2 & 0.1 & - & $\mathbf{1 3 . 4}$ & 0.1 \\
$>40$ & 6.6 & 5.9 & -0.7 & 0.6 & 0.1 & - & - & - & $\mathbf{5 . 7}$ \\
\hline
\end{tabular}


Table 5.3: Effects of Policy Reforms on Tax Revenues and Welfare Costs

\begin{tabular}{lrrrrrrrr}
\hline \hline & \multicolumn{7}{c}{ Percentage change in revenues/costs } \\
\cline { 2 - 8 } & Reform 1 & Reform 2 & \multicolumn{2}{c}{ Reform 3 } & \multicolumn{2}{c}{ Reform 4 } \\
& static & adj. & static & adj. & static & adj. & static & adj. \\
\hline Income Tax & 1.4 & 2.0 & - & 0.3 & - & -4.3 & 26.0 & 19.2 \\
Medicare & 1.4 & -1.6 & - & 1.3 & - & -5.5 & - & -9.5 \\
Family Payment & 0.5 & 1.2 & 1.8 & 1.6 & - & 0.9 & - & 1.5 \\
Family Tax Payment/Assistance & - & - & - & - & - & - & 50.0 & 50.0 \\
Allowances & 2.6 & 0.8 & - & 0.7 & - & 4.9 & - & 5.1 \\
Pensions & - & - & - & 0.2 & - & 0.3 & - & 0.2 \\
Pharmaceutical Allowance & 5.2 & 6.4 & - & 0.7 & - & 2.3 & - & 3.4 \\
Rent Allowance & - & 0.5 & 3.3 & 3.5 & - & 0.5 & - & 1.0 \\
Tax Rebates & -0.2 & -0.2 & - & 0.1 & -87.1 & -86.6 & 2.4 & 3.2 \\
\hline cost change (\%) & 1.3 & 0.6 & 1.0 & 0.5 & -4.3 & 0.5 & -1.7 & 4.1 \\
\hline
\end{tabular}

SPP costs reduce among sole parents. There are some offsetting cost increases (principally from Family Payments), but the net cost to the government is reduced when employment responses are factored into overall costings. Specifically, we find a net cost increase of 1.25 per cent following the SPP rate reduction in the absence of modelled employment responses, but this cost increase reduces to 0.6 per cent once behavioural changes have been accounted for.

\subsubsection{Reform 2: reduce Family Payment tapers $(50 \%$ to $30 \%$ basic, $\& 100 \%$ to $30 \%)$}

This reform to the structure of Family Payments (with a reduction from $50 \%$ to $30 \%$ in the taper for Basic Family Payment, and a reduction from 100\% to $30 \%$ in the taper for higher Family Payments) was implemented in July 2000. Again, we find there to be a positive employment response to this reform, although the effects are more modest than for the first reform discussed earlier. Nevertheless, the estimated net cost to the government is again halved once behavioural responses are taken into account. 


\subsubsection{Reform 3: abolish the Single Parent tax rebate}

The Single Parent tax rate, an additional concession in the tax liabilities among working sole parent households, was set at $\$ 1,243$ per annum in January 2000. As an illustration of the potentially adverse consequences of tax reform on employment incentives, we simulate the behavioural impact of an abolition of the tax rebate on sole parent families. This will penalise sole parent taxpayers by up to $\$ 23.30$ per week, and is likely to have negative employment consequences. The model simulates around 4 per cent of sole parents to move out of the labour market following the abolition. In cost terms, a reform which looked to have generated a net saving for the government (over 4 per cent in net costs in respect of sole parent households) in the absence of any behavioural responses, was found in fact to increase costs once employment responses were taken into account. An inspection of the third columns in Table 5.3 reveals that revenues from income taxation and medicare fall as sole parents withdraw from the labour market, whereas allowance and pension costs increase for those sole parents whose entitlements increase following their reduction in labour market attachment. This is a revealing demonstration of the need to take explicit account of employment responses for a full assessment of the costs of tax and transfer reform.

\subsubsection{Reform 4: increase the basic rate of income taxation from $20 \%$ to $30 \%$}

Next we consider a purely hypothetical reform, used for illustration purposes only. As with the previous reform, we find a considerable employment response to an increase in income taxation, with three per cent of single parent households moving out of the labour market. Costs are of course affected; what looked initially like a revenue earner actually turns out to cost the government money once behavioural responses have fully been accounted for.

\section{Conclusions}

In this paper, we model the labour supply of sole parents as the outcome of a discrete choice among a finite set of hours alternatives. Our estimation strategy controls both for random preference heterogeneity and for fixed costs. A direct quadratic utility function was employed for the individual's preferences. Non-linear tax schedules were handled by 
the use of the MITTS model to generate net incomes over the required hours spectrum. In the absence of controls for fixed costs, the model was found to under-estimate the probability that sole parents would work no hours. All models were found to be consistent with economic theory, and the implied indifference maps were found to conform to the expected pattern, at least over the feasible set of hours and income choices.

The model was used to simulate the likely behavioural responses to the introduction of a range of actual and hypothetical policy reforms in Australia. The simulated employment responses to actual policy reforms introduced recently in Australia are small but positive for sole parent households. Results also suggest that static microsimulation models which do not allow for behavioural responses can lead to non-negligible biases in the financial costs to the government of tax and transfer reforms.

\section{References}

Arrufat, J. L., And A. Zabalza (1986): "Female Labour Supply with Taxation: Random Preferences and Optimising Errors," Econometrica, 54, 47-64.

BeER, G. (1998a): "Is it Worth Working? The Financial Impact of Increased Hours of Work by Married Mothers with Young Children," Australian Bulletin of Labour, 24, 2, 94-111.

(1998b): "The State of Play of Effective Marginal Tax Rates in Australia in 1997," Australian Economic Review, 31, 3, 263-270.

Bingley, P., And I. Walker (1997): "Labour Supply, Unemployment and Participation in in-work Transfer Programmes," Economic Journal, 107, 1375-1390.

Blundell, R., A. Duncan, J. McCrae, and C. Meghir (2000): "The Labour Market Impact of the Working Families' Tax Credit," Fiscal Studies, 21(1), 75-104.

Blundell, R., A. Duncan, and C. Meghir (1992): "Taxation in Empirical Labour Supply Models: Lone Mothers in the UK," Economic Journal, 102, 265-78.

(1998): "Estimating Labour Responses Using Tax Reforms," Econometrica, 66, $827-862$ 
Blundell, R., J. Ham, and C. Meghir (1987): "Unemployment and Female Labour Supply," Economic Journal, 97, 44-64.

Burtless, G., and J. A. Hausman (1978): "The Effect of Taxes on Labor Supply," Journal of Political Economy, 86, 1103-1130.

Callan, T., and A. Van Soest (1996): "Family Labour Supply and Taxes in Ireland," Discussion paper, mimeo, Tilburg University.

Cogan, J. (1981): "Fixed Costs and Labour Supply," Econometrica, 49, 945-964.

Costello, T. H. P. (1998): The Austraalian Taxation System - In Need of Reform. AGPS Canberra.

Creedy, J., And A. Duncan (1999): "The Melbourne Institute Tax and Transfer Simulator," Discussion paper, Melbourne Institute, University of Melbourne.

Creedy, J., A. Duncan, M. Harris, and R. Scutella (2001): "Wage Functions for Demographic Groups in Australia," Australian Journal of Labour, forthcoming.

Dawkins, P., G. Beer, A. Harding, D. Johnson, and R. Scutella (1998): "Towards a Negative Income Tax for Australia," Australian Economic Review, 31, 3, 237257.

Duncan, A., And C. Giles (1996): "Labour Supply Incentives and Recent Family Credit Reforms," Economic Journal, 106, 142-155.

Duncan, A., And C. Giles (1998a): "Alternatives to Family Credit: Tax Credits in the UK Context," in Taxation, In-Work Benefits and the Labour Market: An Analysis of Crucial Design Features, ed. by K. Pichelmann. Vienna: Institute for Advanced Studies(forthcoming).

(1998b): "The Labour Market Impact of the Working Families Tax Credit in the UK," paper presented to the 1998 IIPF Conference, Cordoba, Argentina.

Duncan, A., And G. Stark (2000): "A Recursive Algorithm to Calculate Piecewise Linear Budget Constraints," Discussion Paper W00/11, Institute for Fiscal Studies. 
Duncan, A., And M. Weeks (1997): "Behavioural Tax Microsimulation with Finite Hours Choices," European Economic Review, 41, 619-626.

Flood, L., and T.MaCurdy (1992): "Work Disincentive Effects of Taxes: An Empirical Analysis of Swedish Men," Carnegie-Rochester Conference Series on Public Policy, Number 37.

Gourieroux, C., J. Laffont, and A. Montfort (1980): "Coherency Conditions in Simultaneous Linear Equation Models with Endogenous Switching Regimes," Econometrica, 48, 675-695.

Hajivassiliou, V., And P. RuUd (1994): "Classical Estimation Methods for LDV Models Using Simulation," in Handbook of Econometrics, ed. by R. F. Engle, and D. McFadden, vol. IV. Elsevier Science B.V.

HALL, R. E. (1973): "Wages, Incomes and Hours of Work in the US Labor Force," in Income Maintenance and Labor Supply: Econometric Studies, ed. by C. Cain, and H. Watts. Chicago: Rand McNally.

Hausman, J. A. (1980): "The Effect of Wages, Taxes and Fixed Costs on Women's Labor Force Participation," Journal of Public Economics, 14, 161-194.

Hausman, J. A. (1985): "The Econometrics of Non-Linear Budget Sets," Econometrica, $53,1255-1282$.

Heckman, J. J. (1979): "Sample Selection Bias as a Specification Error," Econometrica, 47, 153-161.

- (1993): "What Has Been Learned About Labor Supply in the Past 20 Years," American Economic Review, 83, 116-121.

HM Treasury (1998): The Working Families Tax Credit and Work Incentives, The Modernisation of Britain's Tax and Benefit System: Number Three. London: HM Treasury.

Ingles, D. (1998): "Overcoming Anomalies in the Interaction of Tax and Social Security," Australian Economic Review, 31, 3, 271-280. 
Keane, M. (1995): "A New Idea for Welfare Reform," Federal Reserve Bank of Minneapolis Quarterly Review, Spring 1995, 2-28.

Keane, M., And R. Moffitt (1997): "A Structural Model of Multiple Welfare Program Participation and Labor Supply," International Economic Review (forthcoming).

Keating, M., and S. Lambert (1998): "Improving Incentives: Changing the Interface of Tax and Social Security," Australian Economic Review, 31, 3, 281-289.

McFadden, D. (1989): "A Method of Simulated Moments for Estimation of Discrete Respsonse Models without Numerical Integration," Econometrica, 57, 995-1026.

Moffitt, R. (1986): "The Econometrics of Piecewise-Linear Budget Constraints," Journal of Business and Economic Statistics, 4, 317-328.

Mroz, T. A. (1987): "The Sensitivity of an Empirical Model of Married Women's Hours of Work to Economic and Statistical Assumptions," Econometrica, 55, 765-799.

Sholz, J. (1996): "In-work Benefit in the United States: the Earned Income Tax Credit," Economic Journal, 106, 156-169.

Stern, N. (1986): "On the Specification of Labour Supply Functions," in Unemployment, Search and Labour Supply, ed. by R. Blundell, and I. Walker, chap. 9, pp. 143-189. Cambridge University Press.

Van Soest, A. (1995): "Structural Models of Family Labour Supply," Journal of Human Resources, 30, 1, 63-83.

Wales, T. J., And A. D. Woodland (1979): "Labour Supply and Progressive Taxes," Review of Economic Studies, 46, 83-95.

\section{Appendix: the Australian Tax and Benefit System}

This section briefly outline the major pertinent elements of Australian tax and transfer system as of time of writing with regard to sole parents (see Centrelink's Web Page at http://www.centrelink.gov.au for further information). 


\subsection{Parenting Payment}

The major benefit payable to sole parents is the Parenting Payment (PP). Current rates are up to $\$ 357.30$ per fortnight (for sole parents). Up to $\$ 124$ (with one child) can be earned without incurring any loss of benefit (which increases by $\$ 24$ for each additional child). Income over this amount reduces the rate of pension payable by 50 cents in the dollar, up to maximum amount of $\$ 849.40$ (plus $\$ 24$ for each additional child).

\subsection{Family Allowance}

The per child allowances are the Family Allowance (FA) ones. These allowances (per fortnight) are $\$ 96.40$ and $\$ 125.40$ for each child aged $0-12$ and $13-15$, respectively. $\$ 7.70$ is additionally paid for each 4th and subsequent child. Each student aged 16-18 earns the minimum rate per child of $\$ 23.50$. Income testing is not applied to those in receipt of any DSS pension, benefit or allowance (for example, PP). Otherwise the income test is as per Table 7.1.

Table 7.1: Income Tests for Family Allowance

\begin{tabular}{ccc}
\hline \hline Number of Children & Annual income limit to get max. FA & Annual income limit at which FA stops \\
\hline 1 & $\$ 23,400$ & $\$ 65,941$ \\
2 & $\$ 24,024$ & $\$ 69,239$ \\
3 & $\$ 24,648$ & $\$ 72,537$ \\
4 & $\$ 25,272$ & $\$ 75,835$ \\
each additional & $\$ 624$ & $\$ 3,298$. \\
\hline
\end{tabular}

Income in excess of that to obtain maximum FA reduces its annual rate by 50 cents in the dollar until the minimum rate has been reached. These income cut-out points also vary by age of dependent child as indicated in Table 7.2.

\subsection{Income Taxation}

Australian income tax is relatively straightforward, being progressive with currently five marginal rates. The 1997-8 tax schedules are reported in Table 7.3 below. 
Table 7.2: Income Tests for Family Allowance (cont)

\begin{tabular}{cccc}
\hline \hline & & Annual income limit in $\$$ Aus: & \\
Age of dependent children: & to get max. FA & beyond only min. rate paid & at which min. rate stops \\
\hline Under 13 & $23,400+(624 \times$ extra child $)$ & $27,191+(4,415 \times$ pec $)$ & $65,941+(3,298 \times$ pec $)$ \\
Students $(13-15)$ & as under 13 & $28,699+(5,923 \times$ pec $)$ & as under 13 \\
Students $(16+)$ & as under 13 & $25,309+(2,533 \times \mathrm{pec})$ & as under 13 \\
\hline
\end{tabular}

Notes: pec $=$ per extra child .

Table 7.3: Income Tax Schedule: 1997-8

\begin{tabular}{ccc}
\hline \hline$k$ & Threshold Income & Marginal Tax Rate \\
\hline 1 & $\$ 5,400$ & 0.20 \\
\hline 2 & $\$ 20,700$ & 0.34 \\
\hline 3 & $\$ 38,000$ & 0.43 \\
\hline 4 & $\$ 50,000$ & 0.47 \\
\hline
\end{tabular}

